\title{
'I just want to be normal' - A qualitative study of pregnant women's blogs who present themselves as overweight or obese
}

Lovisa Lingetun, Madicken Fungbrant, Ing-Marie Claesson and Christina Baggens

The self-archived version of this journal article is available at Linköping University Electronic Press:

http:// urn.kb.se/ resolve?urn=urn:nbn:se:liu:diva-137794

N.B.: When citing this work, cite the original publication.

Lingetun, L., Fungbrant, M., Claesson, I., Baggens, C., (2017), 'I just want to be normal' - A qualitative study of pregnant women's blogs who present themselves as overweight or obese, Midwifery.

https:// dx.doi.org/ 10.1016/j.midw.2017.01.015

Original publication available at:

https://dx.doi.org/10.1016/j.midw.2017.01.015

Copyright: Elsevier

http:// www.elsevier.com/

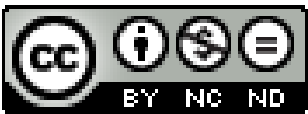




\section{'I just want to be normal'}

\section{- A qualitative study of pregnant women's blogs who present themselves as overweight or obese}

\section{Short title: 'I just want to be normal'}

Lovisa Lingetun ${ }^{1}$ MNSc, RNM, (Midwife)

E-mail address: lovisa.lingetun@gmail.com

Madicken Fungbrant ${ }^{1}$ MNSc, RNM, (Midwife)

E-mail address: madicken.fungbrant@hotmail.com

Ing-Marie Claesson ${ }^{2} \mathrm{PhD}$, RNM, (Midwife)

E-mail adress: ing-marie.claesson@liu.se

Christina Baggens ${ }^{1} \mathrm{PhD}$, RNT, (Senior Lecturer)

E-mail address: christina.baggens@liu.se

${ }^{1}$ Division of Nursing Science, Department of Medical and Health Sciences, Faculty of Health Sciences, Linköping University, Linköping, Sweden

2 Department of Obstetrics and Gynaecology, and Department of Clinical and Experimental Medicine, Linköping University, Linköping, Sweden 


\section{Abstract}

Objective: to describe what pregnant women who present themselves as overweight or obese write about their pregnancy in their blogs.

Setting: Swedish private blogs.

Design: a qualitative study, using 13 Internet blogs as the source of data. Google was used to find the blogs. The blog content was analysed using thematic analysis.

Findings: three main themes were identified: Pregnancy as an excuse, Perspectives on the pregnant body and Becoming a mother. The pregnancy was used as an excuse for breaking the norms, 'I am normal because I am pregnant', and gaining weight, 'I normalise my weight and weight gain'. The women expressed different perspectives of their body through 'For me it is important to look pregnant', 'How others seem to see me' and 'Labelled a risk pregnancy at the antenatal care'. The transition to motherhood was described in 'How the pregnancy affects my life', and there was disappointment when the women experienced 'Unmet expectations'.

Key conclusion: the women described themselves as normal behind the obesity and saw their pregnancy as an excuse for their body size and behaviour. They did not identify themselves as a risk group and they did not recognise the midwife's support during the pregnancy.

Implication for practice: midwives may have to address overweight and obese pregnant women's attitude towards weight and weight gain in weight gain interventions.

Keywords: pregnancy, overweight, obesity, blogs, thematic analysis 


\section{Introduction}

The focus on maternal obesity has increased during the past few decades due to its impact on pregnancy and perinatal outcome (World Health Organization, 2015). The World Health Organization (2015) estimated that in 2014, 40\% of all women worldwide were overweight and $15 \%$ were obese. In Sweden, 34\% of primiparous and $42 \%$ of multiparous women were obese, with a Body Mass Index (BMI) $\geq 30 \mathrm{~kg} / \mathrm{m}^{2}$ in early pregnancy (The Pregnancy Register, 2014). The Institute of Medicine (IOM) has created gestational weight gain (GWG) recommendations that restrict the total weight gain for overweight or obese women to $6-11 \mathrm{~kg}$ and 5-9 kg respectively (Institute Of Medicine, 2009).

Infertility is more common among obese women. They misjudge their ability to become pregnant, and even if they want to have fewer children than the normal weight group they do not have that same number of children (Frisco and Weden, 2013). Maternal pre-pregnant obesity is strongly associated with maternal and foetal morbidity and mortality (Papachatzi et al., 2013; Ng et al., 2014). In comparison with normal weight women, overweight and obese women have an increased risk of pregnancy- related hypertensive disorders and gestational diabetes mellitus (Scott-Pillai et al., 2013). Maternal obesity increases the risk of an altered progression of labour and of having an instrumental delivery (Bogaerts et al., 2012; ScottPillai et al., 2013). Large-for-gestational-age (LGA), premature birth, stillbirth, neonatal death and prolonged stay at the neonatal intensive care unit are complications for the child related to maternal BMI (Scott-Pillai et al., 2013).

Excessive GWG increases the risks for maternal and neonatal outcomes, despite initial BMI (Troung et al., 2015). The risks to obese women can be reduced when GWG is within or below IOM recommendations (Blomberg, 2011; Troung et al., 2015). Even though there is a slightly increased risk of having a baby small-for-gestational-age and premature birth in association with GWG below recommended limits, the benefits outweigh the disadvantages (Beyerlein et al. 2011; Blomberg, 2011; Troung et al., 2015). Obese pregnant women underestimate the consequences of their weight, and their knowledge about GWG restrictions and how to maintain their weight is inadequate (Shub et al., 2013). Not being able to keep to a diet or avoiding gaining weight results in feelings of shame and guilt (Jette and Rail, 2014).

The Swedish antenatal health care system reaches almost $100 \%$ of all pregnant women. Antenatal and delivery care is free of charge. At the antenatal care clinics, healthy pregnant women are advised to attend the regular antenatal program with seven to nine visits to a 
midwife, and, if needed, extra appointments with an obstetrician and/or the midwife. The program prescribes weight controls at recruitment and in pregnancy week 32 and 37. However, in some cases, the state of health indicates more frequent monitoring (Andersson and Svensk förening för obstetrik och gynekologi, 2008).

Obese women are an exposed group at the antenatal care clinic as they feel disrespected and stigmatised by health care providers (Nyman et al., 2010; Furber and McGowan, 2011; Mulherin et al., 2013; Wennberg et al., 2013). Midwives have reported feelings of uncertainty when giving weight and nutritional advice, and a fear of damaging their relationship with the pregnant woman (Heslehurst et al., 2013). Women's encounters with the antenatal care clinic have been shown to result in feelings of being accused, feeling ashamed over their body, sadness and anger (Nyman et al., 2010).

The transition to motherhood is complex and can in different ways be affected by inadequate support and a lack of adequate information. The women's physical and mental health is also an important factor affecting the transition (Schumacher and Meleis, 1994; Meleis et al., 2000).

Mothers spend approximately three hours a day on the Internet (McDaniel et al., 2012). These days, the Internet is an important source of information and a place for sharing personal experiences (Jones and Alony, 2008; Plantin and Daneback, 2009). Finding people in the same situation as themselves and sharing experience-based information helps women feel supported, less alone, and improves their well-being (Nyström and Öhrling, 2006; Jones and Alony, 2008; Plantin and Daneback, 2009; McDaniel et al., 2012). Seeking and sharing experience-based information about pregnancy is considered to have replaced traditional information-seeking from close relatives (Plantin and Daneback, 2009; Doty and Dworkin, 2014). Internet blogs make it possible to limit personal information and create a tailored positive self-presentation and define oneself in a group (Jung et al., 2012).

Women's experiences of pregnancy and encounters with midwives are well explored, as is the discrimination of obese pregnant women. However, to the authors' knowledge, there is no previous research relating to overweight or obese women's pregnancy experiences expressed in blogs. Data from blogs are naturally occurring data (Silverman, 2013), where the writer communicates with an audience who is interested in similar issues and sharing experiences and narratives in a naturally occurring context. Compared to interviews, the stories told in the 
Manuscript 'I just want to be normal'

blogs are genuine, i.e,. they are not constructed in a specific interview situation during an interaction with an interviewer, whose questions and presumed expectations will often influence the respondents’ answers (Lincoln and Guba, 1985). Blogs written by women who present themselves as overweight or obese might therefore give a deeper insight into what issues these women value as important during their pregnancy.

\section{Objective}

The aim of this study was to describe what pregnant women who present themselves as overweight or obese write about their pregnancy in their blog.

\section{Methods}

An explorative qualitative design was chosen. Internet blogs were used as source of data. An inductive qualitative thematic analysis was used to analyse the texts in the blogs (Braun and Clarke, 2006).

\section{Data collection}

The blogs were found via Google during August to October 2014. They were read, and all pregnancy- related posts until the birth were saved in separate documents. Inclusion criteria were private blogs published in Swedish, and the owner of each blog presenting themselves as pregnant and overweight or obese. Exclusion criteria were blogs requiring a password, published texts containing citations, other people's stories, comments, and texts about birth.

Thirteen recent blogs written between 2009 and 2014 were included, and a total of 339 A4 pages of data were used in the analysis. The length of the blogs varied from 1-66 pages. The blogs were characterised by continuous texts written before, during and after the pregnancy, containing pictures and comments from readers of the blog. Only texts about the pregnancy were used in the analysis. Background information was provided by the blogger herself in the blog. The writers of the blogs were 21-40 years old (median age 35 years). Five of the women expected their first child and the other women were multiparous. Seven of the women stated their profession, which ranged from an assistant nurse to an academic. One was a student, whereas the occupation of the remaining five is unknown. One blog contained posts from two 
pregnancies. The time point for the first post about the pregnancy varied in the sample and is presented in Figure 1.

\section{Ethical considerations}

Research on the Internet presents ethical challenges, such as informed consent and maintaining anonymity. Guidelines for Internet research recommended by Codex rules and guidelines for research in Sweden (2015) have been published by the AoIR Ethics Working Committee (Ess and the AoIR Ethics Working Committee, 2002; Markham \& Buchanan, 2012), The National Committee for Research Ethics in the Social Sciences and the Humanities (2014), and Bruckman (2002). Texts published on the Internet can be considered public (American Association for the Advancement of Science, 1999; Eysenbach and Till, 2001; Bruckman, 2002; Ess and the AoIR Ethics Working Committee, 2002; Eastham, 2011; Bradley and Carter, 2012; Markham \& Buchanan, 2012). By making texts available on the Internet, blog owners give an 'implied consent'. Therefore, the authors refrained from requesting informed consent. With respect for the bloggers'privacy, blogs requiring a password were excluded (Eastham, 2011). The study was performed in accordance with the Swedish legislation of non-invasive studies (Swedish Code of Statutes, 2003/2008). The authors have protected and preserved the integrity and anonymity of the blog owners by removing any details that could compromise their identity. Citations from blogs originally written in Swedish have been translated into English, and the authors have made sure that they are not traceable without losing the essence of the expressions.

\section{Data analysis}

The structure of the six phases of Brown and Clarke's (2006) thematic analysis model were followed, see Table 1. A test analysis was first made separately by the two first authors. The fourth author analysed the same material and the findings were compared. All data were coded and sorted into themes that were then organised in relation to each other. There was continuous movement back and forth between the six phases of the model. The authors made sure that the themes were internally coherent, consistent and distinctive from each other, and true to the collected data.

Being more than one author was one way of accomplishing reflexivity by reflecting critically on one's own knowledge and personal values that could affect the data analysis (Polit and Tatano Beck, 2012). To reduce personal bias and increase credibility there was an ongoing 
Manuscript 'I just want to be normal'

critical discussion of the findings and themes between the four authors. The 15-point checklist of criteria for a good thematic analysis suggested by Braun and Clarke (2006) was considered.

\section{Findings}

The main themes and sub-themes are presented in Table 2.

\section{Pregnancy as an excuse}

\section{I am normal because I am pregnant}

The women described the fact that they had become pregnant as a major confirmation of normal bodily function and of good health. They were aware of the infertility risk related to overweight, but once pregnant the overall risks related to overweight did not apply to them. They described their body as normal in terms of now becoming pregnant, always being healthy, and having normal results at antenatal check-ups.

The women described themselves as normal behind the obesity and saw the pregnancy as an excuse for their body size. It was now allowed to be obese without being judged for gaining weight. The pregnancy became a shield, a mantra, and an excuse. Some took advantage of their body size to keep the pregnancy a secret for a longer period of time.

Pregnancy provided an excuse for a behaviour that they felt differs from the norm. They normalised manners and habits such as eating sweets, or staying on the sofa rather than doing exercise. Pregnancy as an excuse was described by the women to be more generally accepted in a social context.

When you are pregnant it's ok to allow yourself to eat. But not without limits, I know. Well, well. That's what I say about almost everything now. When I’m angry: “It's because I'm pregnant!” When I cry: “It's because I'm pregnant”. When I go to the front of the toilet queue: "I’m pregnant" (Annie).

\section{I normalise my weight and weight gain}

Gaining weight during pregnancy was seen to be normal and unavoidable because of the process of a normal pregnancy. The weight gain was something they could not control or do anything about, and therefore they did not expect themselves to follow given GWG limits. 
How can I avoid gaining weight, the baby weighs $1 \mathrm{~kg}$, maybe even more, and all the amnion fluid that I've a lot of according to the ultra sound. You get extra blood volume, fluids, placenta... well, how can I avoid gaining weight? ... All the tests are ok. I don't understand, what's the problem? Or is it just that I turn a blind eye? (Frida).

The women expressed that a lack of control of their weight was an excuse for not having to care about it. After the baby was born they would lose the weight, and therefore it was not seen as a problem. The pregnancy justified unhealthy eating and the women believed that their unhealthy eating would not affect the foetus. When going to the antenatal care clinic, they were afraid of what the midwife would say in case they had gained weight or that they would receive hurtful comments about their weight.

The women viewed the fact that they carried extra kilos as a resource, for example, when feeling ill and vomiting. They interpreted information about their high symphysis-fundus measures or LGA expectancy only as positive, because it is an indication of functional pregnancy and good conditions. Some had general discussions about labour, how they wanted it to be, what kind of pain relief they may need, and expressed a wish for a vaginal birth. They did not appear to consider their weight or GWG as a problem for giving birth.

\section{Perspectives on the pregnant body}

For me it is important to look pregnant

It was important that others could see that they were pregnant, and the women were therefore concerned whether others would wonder if they were obese or pregnant. The women discussed how pregnant they looked and longed for their stomach to grow even more. As the stomach changed shape during the pregnancy, the women felt relieved and satisfied with their body. They were disappointed when they still looked obese and described that they were looking forward to having a pregnant stomach, as that would affect how others viewed them.

Unfortunately, the pregnancy makes my belly-fat show even more. I long for my belly to look like a pregnant belly. Then I can wear tight clothes without making people wonder “Is she fat or is she pregnant?” (Doris-2).

There was an evident insight about how they looked and may appear to others when they saw themselves in mirrors or photographs. Meeting other pregnant women generated feelings of being unpleased and dissatisfied with their own body. They felt that in comparison, their 
Manuscript 'I just want to be normal'

stomach was not a pregnant stomach and this added to the wish to look more pregnant. When they compared themselves with others or had reached the late stages of pregnancy, the women described themselves in negative body associations, expressed with humorous metaphors or in harsh terms. Some felt huge, gigantic, or ugly, and others compared themselves to large animals or animated figures. The women received encouraging comments from their partners, but they dismissed them by accusing them of being biased.

\section{How others seem to see me}

When the women visited public places, they felt odd and singled out as "fat people". They experienced that people stared and judged them because of their weight and for not being as healthy as they should be. The feeling of being observed and judged made the women uncomfortable, upset and ashamed.

It's because I'm pregnant, that is what it is... Otherwise I wouldn't have dared to buy that much unnecessary food at once.. Because then people think: "Fat people like her shouldn't eat stuff like that”... (Doris -1).

Comments about their pregnant body and questions about the size of the baby or if they were expecting twins were common. The comments varied in terms of the stomach being too small or too big for the time of pregnancy. Hearing these comments made the women feel upset and displeased with their body. They experienced that people around them did not see them as a person, but only as an obese pregnant woman, which was an excuse for them to comment on their body.

Labelled a risk pregnancy at the antenatal care.

At the antenatal care clinic, the women felt singled out as a special group, labelled a risk pregnancy because of their weight. The women were warned that there would be problems listening to the foetus' heart sound, measuring symphysis-fundus, and carrying out ultrasound scans because of their body size. The midwives’ comments on their weight or BMI upset the women.

Last time at the antenatal care clinic I had gained 4 kilos in total and that made my midwife concerned, because I shouldn't gain weight at all. Not when you're as fat as I am. But when I look at myself in the mirror and in pictures, I'm not sure I agree. Am I 
really severely overweight? The midwife actually said: "I will write in your journal that you are overweight, just so that you know!” (Julia).

The women were told by the midwife that there would be extra check-ups because of their risk pregnancy. Despite this, the women expressed suspicion towards research and what scientists really know about the effect of overweight. Moreover, they felt that all the extra check-ups were unnecessary and unimportant. The positive side of extra check-ups was that they could see or hear their child an extra time. The women perceived the midwife as nervous and alarmed about their BMI and GWG, which created unnecessary anxiety about the risks in relation to their weight. The women expressed concern of how it would affect their own and the foetus' development.

In their meetings with the midwife, they were told about the importance of BMI and that there are GWG restrictions, something the women found to be irrelevant. The women felt that the midwife's focus on BMI blinded them to the rest of the person, and they found the GWG limits and recommendations about food and exercise to be unreasonable and unspecific. This provoked feelings of anger towards the midwife and the relationship between the woman and the midwife became strained.

Going to the antenatal care clinic caused distress about how they would be met by health care providers. Being weighed caused anguish and it was something they wanted to avoid. The focus on weight made the women confused about what was considered an acceptable weight gain in a particular gestational week. There was a feeling of worthlessness if they could not follow the weight restrictions the midwife had given them. They were therefore worried about what the midwife would say when they had gained weight.

\section{Becoming a mother}

\section{How the pregnancy affects my life}

The women expressed the psychological life change in terms of the new role of motherhood, wanting to be their best for their unborn child and expectations of the life ahead. Mixed feelings occurred, described by the women as terror and anticipation at the same time when thinking about becoming a mother. Ultrasound scans had a significant role in the realisation that they were becoming a mother. The feeling of motherhood grew stronger the closer they came to the predicted date of birth. 
The women used mobile phone applications and Internet sites to gain information about pregnancy. Thoughts about name, sex, appearance and personality were an ongoing process. They described how they longed to meet their unborn child. All blogs contained countdowns of the time left to the predicted date of birth and important events such as the first meeting with the midwife, ultrasound scans, listening to the foetus' heart sound, and feeling the first foetal movements. Passing the time point for having a premature baby was also a great relief.

The physical change resulting from pregnancy was mentioned when the body became a hindrance in everyday life. The first months of pregnancy were dominated by nausea, being tired, and therefore not being able to go to work. Later on during the pregnancy, other pregnancy-related symptoms made everyday life hard to manage. Despite being careful with their diet and intending to restrict gestational weight gain, the pregnancy was characterised by concerns about complications, which took all the pleasure out of the pregnancy.

I gained only 4 kilos during my pregnancy. I was extra careful with what and when I ate and added lots of iron to my food because I had low blood values. But I spent 9 months holding my breath, terrified that something would go wrong. That is not what I would call a normal pregnancy (Ida).

The pregnancy affected the women's social sphere, and their relationships to other people changed. This was caused by the pregnancy process and the way it changed the women, both physically and psychologically. The women expressed feelings of being misunderstood or missing the old me.

Having a baby was described as the motivation to endure the pregnancy process, especially when the change to their lives was challenging. The birth was seen as an end of a challenging life change and a start of something new.

\section{Unmet expectations}

The women expected pregnancy to be a positive and enjoyable time in life, when one should be happy. Pregnancy was not seen as a time for demands, but a time for pleasure, euphoria, dreams and allowing oneself to give in to desires. Life changes should be enjoyable without having to suffer.

The women took pleasure in eating sweets and food described by themselves as unhealthy. Feelings of disappointment, frustration and sadness emerged when the pregnancy did not meet 
up to their expectations. The women thought they could enjoy eating sweets during their pregnancy, but the midwife gave recommendations that made the pregnancy demanding instead of pleasurable. Their pregnancy was ruined by all the demands and restrictions, and it was therefore perceived as abnormal. Furthermore, they felt distressed about their encounters with the professionals.

Now, I recognise the need to talk about being pregnant and fat. Most pregnant women are a bit worried, but for us fat people the worry is also about how we will be met by health care staff. That's why I choose to share some of my thoughts and experiences (Karin).

Negative aspects were harder to endure and the women were not prepared for all the problems that occurred. The women were not as happy as they thought they would be.

\section{Discussion}

Data from blogs were used in this study as this is considered a new source of information in health research, due to the genuine language and similarities with diaries (Eastham, 2011). According to a scoping review, blogs are often used in qualitative health research because data from blogs illustrate experiences, perceptions and feelings (Wilson, et al., 2015). The use of blogs in a health research context gives new and unique access to women's thoughts and experiences by naturally occurring data (Silverman, 2013), without the influence of a researcher's presence (Eysenbach and Till, 2001). Using blog owners’ own words as material is beneficial as this may provide a more personal picture of the experience of being pregnant and overweight (Bronstein, 2013). Disadvantages with using blog material concern the credibility of the blog owners' identity (Polit and Tatano Beck, 2012). The authors have regarded the blogging women as being overweight in the analysis. This may be a limitation in the study because weight is not verified. Furthermore, according to Jung et al. (2012), people might present themselves more favourably than truthfully in their blogs. It is the nature of the Internet that people can be anonymous by using a pseudonym, but most blogs contain pictures and personal information that reveal their identity (Bronstein, 2013). Our sample represents pregnant women of different ages, which strengthens our findings by a variety of data (Polit and Tatano Beck, 2012). The small sample size (13 blogs) is, however, a limitation. It is also a limitation that objective background data about the bloggers is unknown. Furthermore, 
women who do not have access to a computer might not be included in the study. Therefore, transferability of the present study is restricted (Lincoln \& Guba, 1985).

The first main theme, Pregnancy as an excuse, highlights the fact that the women did not consider taking responsibility for their GWG. Our findings indicate that pregnancy was a positive and longed-for state for the women, because of the approval of their larger body size. It became acceptable to be obese and gain weight. This attitude and perspective have been confirmed in another study, where women perceived themselves as being excused for being obese when pregnant (Hodgkinson et al., 2013). Pregnancy becomes an accepted excuse for breaking norms, eating habits, and weight gain. The perspective of GWG being equal to a healthy pregnancy is consistent with a previous study (Jette and Rail, 2014). Accepting the loss of control and viewing themselves as victims of the pregnancy process include gaining weight, eating for two, having cravings and giving in to pleasures.

The second main theme, Perspectives on the pregnant body, represents the women's fixation with their appearance in contact with other people. It was important to look pregnant as it could support their own body image of being normal due to the pregnancy.

Pre-pregnancy dissatisfaction with one's body image has been shown to be maintained prior to and during pregnancy (Duncombe et al., 2008). In our findings, concern about stomach size and shape is central. The women seemed to feel more dissatisfied with their own body when they compared themselves to other women (Lev-Ari et al., 2014). BMI is a predictor for women's self-esteem, where a high BMI is associated with lower self-esteem (Henriques et al., 2013). High BMI, feeling unattractive, and having low self-esteem are associated with higher GWG (Henriques et al., 2013; Hill et al., 2013; Sui et al., 2013).

The women in our study experienced discomfort when other people stared, and they felt judged by their body size. Overweight pregnant women are reported to feel stigmatised and they are an exposed group even before they become pregnant (Nyman et al., 2010; Mulherin et al., 2013; Wennberg et al., 2013). The findings from our study verify that this group is sensitive and exposed to judgemental attitudes and treatment.

Being labelled a risk pregnancy at the antenatal care clinic represents the women's and midwives' conflicting perspectives of the pregnant body. Women do not like to be defined as obese and have different definitions of obesity than health care providers (Kominiarek et al., 2015). Midwives have expressed how the concept of normality in relation to body size and 
weight has shifted. Obese childbearing women are an increasing group and what used to be considered a risk is now perceived as normal (Schmied et al., 2011). This is reflected in our findings, where the women expressed that they think of themselves as normal and that they do not have to care about risks related to their overweight or obesity. It seems that some of the overweight childbearing women did not identify themselves as a risk pregnancy. In our findings, there is little or no risk awareness related to weight or GWG. The women underestimated the consequences and did not see themselves as large although they were told that they were by the midwife, which is confirmed by other studies (Shub et al., 2013; Sui et al., 2013). Being aware of their overweight can protect women from excessive GWG (Hill et al., 2013). Neglecting risks and other threats related to their weight may be easier if the woman talks about herself as normal (Hodgkinson et al., 2013).

Midwives have reported feeling uncomfortable talking about weight and GWG limits (Heslehurst et al., 2013). This can make the midwife choose alternative words for obesity, making it seem less dangerous (Kominiarek et al., 2015). Our findings confirm that the midwife/woman communication is not without difficulties. The women felt judged and that the midwife placed them in a special category. They were told how difficult it would be for the midwife to do their job, how much extra work that would be required, both during the pregnancy and the delivery, because of the risks related to their weight. In a study by Lindhardt et al. (2013), overweight or obese pregnant women expressed how they were met with accusations by health care providers. In contrast to our findings, these women felt that they were poorly informed about weight- related risks and extra check-ups, which suggests that talking about the GWG with obese or overweight pregnant women is a hard task for midwives.

Mills et al. (2013) described that obese women do not take control over their GWG. The women in the current study were confused and did not appear to understand the GWG limits or how to maintain their weight. This has also been expressed in a previous study, where women expected a weight gain over the recommended limits and did not believe that they could control their GWG (Kominiarek et al., 2015). Lindhardt et al. (2013) have confirmed that a lack of advice and helpful information causes confusion, frustration, and feelings of insufficiency. The women in our study interpreted the midwives' concern and anxiety as threatening to the child's development. Instead of taking heed of the advice and information, they were provoked and expressed anger towards the worried midwife, questioning their 
expertise and the reliability of facts. Information seemed to have an adverse effect and the women sometimes wrote about how they defied recommendations.

The ethical challenge for midwives is to provide political and sufficient care for women who do not identify themselves as a risk pregnancy. Weight management with continuous support, feedback and information is important to help women change their habits, but it is pointed out that the women must be willing to restrict their own GWG (Claesson et al., 2008). Our findings indicate that overweight women are not receptive to weight restrictions. The women's motivation was to look pregnant. Claesson et al. (2008) have suggested that the focus should be on the women's goals for weight restriction rather than achieving the midwives' guidelines, which requires active involvement from both women and midwives.

The theme Becoming a mother describes the normal transition to motherhood with a feeling of disappointment when expectations were unmet by the pregnancy experience. The women expressed being out of control in their daily life, which may be due to the natural transition to motherhood, where loss of control is felt in the first trimester (Schneider, 2002). The women in our study expressed the same expectations and feelings during their pregnancy as described in Schneider's study (2002), implying that these women went through the process of becoming a mother and that being overweight did not have a decisive impact on the transition. This finding is important and worth considering as midwives have to be aware that overweight or obese pregnant women seem to have the same experiences and expectations of their pregnancy as most women (Hildingsson et al., 2014).

The women in our study were emotionally affected by the midwife, the society, and their pregnancy. They had not foreseen the challenges and how their pregnancy would be received by the midwife. Expecting mothers want a caring, proactive midwife who gives them psychological support, including help with pregnancy changes and preparations for the birth and motherhood (Seefat-van Teeffelen et al., 2011).

The women used their blogs to express and share experiences about their pregnancy. They expressed relief and were satisfied when others commented, making them feel less alone. Blogging can have an effect on feelings of loneliness, well-being and social support (Jung et al., 2012). Sharing life experiences online gives the blog writer a purpose and a feeling of being meaningful to others in similar situations (Yu et al., 2011). Blogging can be seen as an expression for seeking contact, satisfying the need for disclosure, expressing personal opinions, and a medium for seeking affiliation (Chen, 2012; Chen, 2015). Blogging might, 
however, also be a disadvantage among pregnant women who present themselves as overweight or obese, as well as among women who use the Internet perinatally, as they might be reinforced in their way of thinking and are seldom questioned by other bloggers, as illustrated in a community of food bloggers (Lynch, 2010). Furthermore, as blogs mainly contain personal experiences, correct medical information might not be spread among bloggers or might be misunderstood (Gruzd et al., 2012). Searching for information on the Internet might also lead to anxiety because of the amount of information and an awareness about all the things that can happen, as well as signs of potential symptoms (Barkin and Jani, 2016). The blog may present an opportunity to create a tailored identity where it is possible to choose what images to show or stories to tell (Jung et al., 2012). The construction of a wanted identity could be one explanation why the women in our study described themselves as normal. It may be a desire to be recognised as normal by others, as they usually feel odd and singled out. This may be a subject for further research.

\section{Conclusion}

In this study we found that women who presented themselves as overweight felt normal by their pregnancy and used their pregnancy as an excuse for not taking responsibility for their weight and GWG. They expressed a desire to be normal and look pregnant. The women did not identify their pregnancy as a risk-pregnancy and wanted the pregnancy to be considered as normal. The midwives’ support during pregnancy was not recognised, and information about GWG seemed to have an adverse, provocative effect.

\section{Clinical implications}

Blogging may provide an insight into how overweight or obese pregnant women receive health care information, and the effect of this information. The findings suggest that midwives may have to address women's attitude towards weight and weight gain and be aware of women's body image in weight gain interventions. It may be important that midwives create a balance between allowing women to feel comfortable with their pregnant body and providing adequate supporting care, especially for these women who regard their bodies as unproblematic.

Further research is needed to develop new approaches to how midwives can help women with weight management.

\section{Contributions}


Manuscript 'I just want to be normal'

Study design: CB, MF, LL; data collection: MF, LL; analysis: CB, IMC, MF, LL, and manuscript preparation: CB, IMC, MF, LL

\section{Conflict of interest}

The authors have no conflict of interest to report. 
Manuscript 'I just want to be normal'

\section{References}

American Association for the Advancement of Science. (1999). Ethical and legal ascpect of human subjects research on the internet: A report of a workshop. Retrieved 08 28, 2014, from http://www.aaas.org/page/ethical-and-legal-aspects-human-subjects-research-cyberspace.

Andersson, A. and Svensk förening för obstetrik och gynekologi (2008). Mödrahälsovård, sexuell och reproduktiv hälsa. Stockholm: Svensk förening för obstetrik och gynekologi. (In Swedish).

Barkin, J.L., Jani, S. (2016). Information Management in New Motherhood: Does the Internet help or Hinder? Journal of the American Psychiatric Nurses Association, 22(6), 475-482.

Beyerlein, A., Schiessl, B., Lack, N., von Kries, R. (2011). Associations of gestational weight loss with birth-related outcome: a retrospective cohort study. BJOG: an International Journal of Obstetrics and Gynaecology, 118(1),55-61.

Blomberg, M. (2011). Maternal and neonatal outcomes among obese women with weight gain below the new Institute of Medicine recommendations. Obstetrics Gynecology, 117(5),10651070.

Bogaerts, A., Witters, I., Van den Bergh, B., Jans, G., Devlieger, R. (2012). Obesity in pregnancy: Altered onset and progression of labour. Midwifery, 29(12),1303-1313.

Bradley, S. K., Carter, B. (2012). Reflections on the ethics of Internet newsgroup research. International Journal of Nursing Studies, 49,625-630.

Braun, V., Clarke, V. (2006). Using thematic analysis in psychology. Qualitative Reseach in Psychology, 3(2),77-101.

Bronstein, J. (2013). Personal blogs as online presences on the internet. Exploring selfpresentation and self-disclosure in blogging. Aslib Proceedings, 65(2),161-181.

Bruckman, A. (2002). Ethical Guidelines for Research Online. Retrieved 10 18, 2015 from http://documents.kenyon.edu/provost/irb_ethics_online.pdf

Chen, G. M. (2012). Why do women write personal blogs? Satysfying needs for selfdisclosure and affiliation tell part of the story. Computers in Human Behaviour, 28(1),171180. 
Chen, G. M. (2015). Why do women bloggers use social media? Recreation and information motivations outweigh engagement motivations. New Media Society, 17(1),24-40.

Claesson, I. M., Josefsson, A., Cedergren, M., Brynhildsen, J., Jeppson, A., Nyström, F., et al. (2008). Consumer satisfaction with a weight-gain intervention programme for obese pregnant women. Midwifery, 24(2),163-167.

Codex, Centre for Research Ethics \& Bioethics (2015). Codex - Rules and Guidelines for Research. Retrieved 10 08, 2015 from http://codex.vr.se/en/forskninghumsam.shtml

Doty, J. L., Dworkin, J. (2014). Online Social Support for Parents: A Critical Review. Marriage Family Review, 50(2),174-198.

Duncombe, D., Wertheim, E.H., Skouteris, H., Paxton, S.J., Kelly, L. (2008). How Well Do Women Adapt to Changes in Their Body Size and Shape across the Course of Pregnancy? Journal of Health Psychology, 13(4), 503-515.

Eastham, L. (2011). Research using blogs for data: Public documents or private musings? Research in Nursing and Health, 34,353-361.

Ess, C. and the AoIR Ethics Working Committee (2002). Ethical Decision-Making and Internet Research. Recommendations from the AoIR Ethics Working Committee. Retrieved 10 08, 2015 from http://aoir.org/reports/ethics.pdf

Eysenbach, G., Till, J. E. (2001). Ethical issues in qualitative research on internet communities. Brittish Journal of Medicine, 323,1103-1005.

Frisco, M. L., Weden, M. (2013). Early Adult Obesity and U.S. Women’s Lifetime Childbearing Experiences. Journal of Marriage and the Family, 75(4),920-932.

Furber, C. M., McGowan, L. (2011). A qualitative study of experiences of women who are obese and pregnant in the UK. Midwifery, 27,437-444.

Gruzd, A., Black, F.A., Yen Le, T.N., Amos, K. (2012). Investigating biomedical research literature in the blogosphere: a case study of diabetes and glycated haemoglobin (HbA1c). Journal of the Medical Library Association, 100, 34-42. 
Henriques, A., Alves, E., Barros, H., Azevedo, A. (2013). Women's satisfaction with bodyimage before pregnancy and body mass index 4 years after delivery in the mothers of generation XXI. Public Library of Science, doi:10.1371/journal.pone.0070230.

Heslehurst, N., Russell, S., McCormack, S., Sedgewick, G., Bell, R., Rankin, J. (2013). Midwives perspectives of their training and education requirements in maternal obesity: A qualitative study. Midwifery, 29,736-744.

Hildingsson, I., Andersson, E., Christensson, K. (2014). Swedish women’s expectations about antenatal care and change over time - A comparative study of two cohorts of women. Sexual \& Reproductive Healthcare, 5, 51-57.

Hill, B., Skouteris, H., McCabe, M., Fuller-Tyszkiewicz, M. (2013). Body image and gestational weight gain: A prospective study. Journal of Midwifery Women's Health, 58,189194.

Hodgkinson, E. L., Smith, D. M., Wittkowski, A. (2013). Women's experiences of their pregancy and postpartum body image: a systematic review an meta-synthesis. Bio Med Central Pregancy and Childbirth, doi:10.1186/1471-2393-14-330.

Institute Of Medicine. (2009). Weight gain during pregnancy: Reexamining the Guidelines. Retrieved 03 09, 2015, from Resource sheet : http://www.iom.edu/en/Reports/2009/WeightGain-During-Pregnancy-Reexamining-the-Guidelines.aspx.

Jette, S., Rail, G. (2014). Resisting, reproducing, resigned? Low-income pregnant women's discursive constructions and experiences of health and weight gain. Nursing Inquiry, 21(3),202-211.

Jones, M., Alony, I. (2008). Blogs - the new source of data analysis. Journal of issues of informing sciences and information technology, 5,433-446.

Jung, Y., Song, H., Vorderer, P. (2012). Why do people post and read personal messages in public? The motivation of using blogs and its effects on users' loneliness, beloning, and wellbeing. Computers in Human Behaviour, 28(5),1626-1633.

Kominiarek, M. A., Gay, F., Peacock, N. (2015). Obesity in pregnancy: A qualitative approach to inform an intervention for patients and providers. Maternal and Child Health Journal, doi:10.1007/s10995-015-1684-3. 
Lev-Ari, L., Baumgarten-Katz, I., Zohar, A. H. (2014). Mirror, mirror on the wall: How women learn body dissatisfaction. Eating Behaviours, 15(3),397-402.

Lincoln, Y.S., Guba, E.G. (1985). Naturalistic inquiry. Beverly Hills, Ca: Sage Publications.

Lindhardt, C. L., Rubak, S., Mogensen, O., Lamont, R. F., Joergensen, J. S. (2013). The experience of pregnant women with a body mass index $>30 \mathrm{~kg} / \mathrm{m}^{2}$ of their encounters with healthcare professionals. ACTA Obstetricia et Gynecologica Scandinavia, 92(9),1101-1107.

Lynch, M. (2010). Healthy habits or damaging diets: An exploratory study of a food blogging community. Ecology of Food and Nutrition, 49, 316-335.

Marckham, A. \& Buchanan, E. (2012). Ethical Decision-Making and Internet Research. Recommendations from the AoIR Ethics Working Committee (Version 2). Retrieved 10 08, 2015 from http://aoir.org/reports/ethics2.pdf

McDaniel, B. T., Coyne, S. M., Holmes, E. K. (2012). New mothers and media use: Association between blogging, social networking, and maternal well-being. Matern Child Health Journal, 16,1509-1517.

Meleis, A. I., Sawyer, L. M., Im, E., Hilfinger Messias, D. K., Schumacher, K. (2000). Experiencing transitions: an emerging middle-range theory. Advances in Nursing Science, 23(1),12-28.

Mills, A., Schmeid, V. A., Dahlen, H. G. (2013). 'Get along us', women's experiences of being overweight and pregnant in Sydney, Australia. Maternal and Child Nutrition, 9,309-321.

Mulherin, K., Miller, Y. D., Barrlow, F. K., Diedrichs, P. C., Thompson, R. (2013). Weight stigma in maternity care: women's experiences and care providers' attitudes. BMC Pregnancy and Childbirth, doi:10.1186/1471-2393-13-19.

Ng, S., Cameron, C., Hills, A., McClure, R., Scuffham, P. (2014). Socioeconomic disparities in prepregnancy BMI and impact on maternal and neonatal outcomes and postpartum weight retention: the EFHL longitudinal birth cohort study. BMC Pregnancy Childbirth, doi:10.1186/1471-2393-14-314.

Nyman, V. M., Prebensen, Å. K., Flensner, G. E. (2010). Obese women's experiences of encounters with midwives and physicians durin pregnancy and childbirth. Midwifery, 26,424429. 
Nyström, K., Öhrling, K. (2006). Parental support: mothers’ experience. Journal of Telemedicine and Telecare, 12(4),194-197.

Papachatzi, E., Dimitriou, G., Dimitropoulos, K., Vantarakis, A. (2013). Pre-pregnancy obesity: Maternal, neonatal and childhood outcomes. Journal of Neonatal- Perinatal Medicine, 6,203-216.

Plantin, L., Daneback, K. (2009). Parenthood, information and support on the internet. A litterature review of research on parents and professionals online. BMC family practice, doi:10.186/1471-2296-10-34.

Polit, D. F., Tatano Beck, C. (2012). Nursing research 9.ed. Philadelphia: Wolters Kluwer Health/ Lippincott Williams Wilkins.

Schmied, V. A., Duff, M., Dahlen, H. G., Mills, A. E., Kolt, G. S. (2011). 'Not waving but drowning': a study of the experiences and concerns of midwives and other health professionals caring for obese childbearing women. Midwifery, 27,424-430.

Schneider, Z. (2002). An Australian study of women's experiences of their first pregnancy. Midwifery, 18,238-249.

Schumacher, K. L., Meleis, A. I. (1994). Transition: A Central Concept in Nursing. The journal of nursing scholarship, 26(2),119-127.

Scott-Pillai, R., Spence, D., Cardwell, C. R., Hunter, A., Holmes, V. A. (2013). The impact of body mass index on maternal and neonatal outcomes: a retrospective study in a UK obstetric population, 2004-2011. BJOG: an International Journal of Obstetrics and Gynaecology, 20(8),932-939.

Seefat-van Teeffelen, A., Nieuwenhuijze, M., Korstjens, I. (2011). Women want proactive psychological support from midwives during transition to motherhood: a qualitative study. Midwifery, 27,e122-e127.

Shub, A., Huning, E., Campell, K., McCarthy, E. (2013). Pregnant women's knowledge of weight, weight gain, complications of obesity and weight management strategies in pregnancy. BMC reserach notes, doi:10.1186/1756-0500-6-278.

Silverman, D. (2013). Doing qualitative research 4.ed. Thousand Oaks, Ca: Sage Publications. 
Manuscript 'I just want to be normal'

Sui, Z., Turnbull, D., Dodd, J. (2013). Effect of body image on gestational weigh gain in overweight and obese women. Women and Birth, 26(4),267-272.

Swedish Code of Statuses (2003/2008). The Act Concerning Ethical Review of Research Involving Humans (2003:460/2008:192). Retrieved 10 18, 2015, from http://www.epn.se/start/

The National Committee for Research Ethics in the Social Sciences and the Humanities (NESH). (2014). Ethical Guidelines for Internet Research. Retrieved 10 18, 2015, from https://www.etikkom.no/forskningsetiske-retningslinjer/etiske-retningslinjer-for-forskning-painternett/

The Pregnancy Register. (2014). The Pregnancy Register. Retrieved 03 20, 2015, from Annual report 2013: https://www.medscinet.com/GR/dokumentarkiv.aspx

Troung, Y. N., Yee, L. M., Caughey, A. B., Cheng, Y. W. (2015). Weight gain in pregancy: does the Institute of Medicine have it right? American Journal of Obstetrics and Gynecology, 212(3),362.e1-8.

Wennberg, A. L., Lundqvist, A., Högberg, U., Sandström, H., Hamberg, K. (2013). Women's experiences of dietary advice and dietary changes during pregnancy. Midwifery, 29,10271034.

Wilson, E., Kenny, A., Dickson-Swift, V. (2015). Using blogs as a qualitative health research tool: A scooping review. International Journal of Qualitative Methods, 1-12, doi:

10.1177/1609406915618049.

World Health Organization. (2015). Obesity and overweight. Retrieved 07 05, 2015, from http://www.who.int/mediacentre/factsheets/fs311/en/.

Yu, J., Taverner, N., Madden, K. (2011). Young people's views on sharing health-related stories on the internet. Health and Social Care in the Community , 19(3),326-334. 


\section{Figure 1}

Manuscript: 'I just want to be normal'

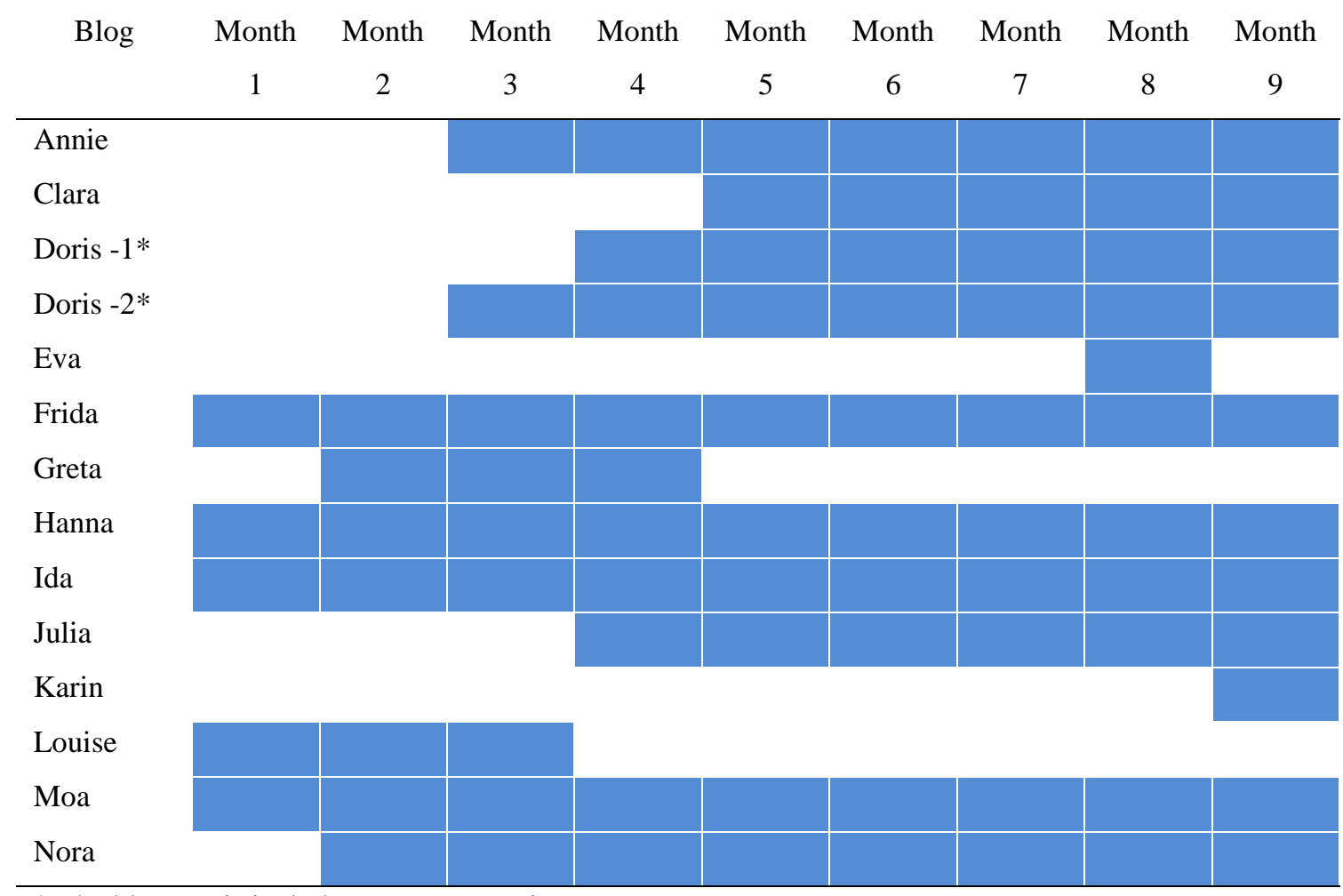

* The blog Doris includes two pregnancies.

Figure 1. Overview of the blogs over time. Please note that the women's names are fictitious. 
Table 1

Manuscript: 'I just want to be normal'

Table 1. The six phases of thematic analysis*

\begin{tabular}{ll}
\hline Phase Description of the process \\
\hline
\end{tabular}

1. Familiarisation with Data was read and re-read

the data

2. Generating codes Interesting features across the entire data set were coded systematically, data relevant to codes was sorted unto each code

3. Searching for themes Codes were arranged into potential themes

4. Reviewing themes The initial themes were checked in relation to the entire data. Further, they were changed in order to achieve coherent, consistent and identifiable distinctions between the themes

5. Defining and naming An ongoing analysis was undertaken to refine each theme that generated themes clear definitions and names for each theme

6. Producing the report A final analysis was made by writing the report. This involved selecting vivid and compelling extracts from data and a presentation of interesting features related to the aim of this research and literature

* according to Braun \& Clarke (2006). 


\section{Table 2}

Manuscript: 'I just want to be normal'

Table 2. Main and sub-themes

\begin{tabular}{|c|c|}
\hline Main themes & Sub-themes \\
\hline \multirow[t]{2}{*}{ Pregnancy as an excuse } & I am normal because I am pregnant \\
\hline & I normalise my weight and weight gain \\
\hline \multirow[t]{3}{*}{ Perspectives on the pregnant body } & For me it is important to look pregnant \\
\hline & How others seem to see me \\
\hline & Labelled a risk pregnancy at the antenatal care \\
\hline \multirow[t]{2}{*}{ Becoming a mother } & How the pregnancy affects my life \\
\hline & Unmet expectations \\
\hline
\end{tabular}

